ARTICLE

httpst//doi.org/10.1038/s41467-022-28050-z

\title{
Solvent-free bottom-up patterning of zeolitic imidazolate frameworks
}

Yurun Miao (1) 1,7, Dennis T. Lee (1) 1,7, Matheus Dorneles de Mello (10) 2,3, Mueed Ahmad 2,4, Mohammed K. Abdel-Rahman ${ }^{5}$, Patrick M. Eckhert (10 ${ }^{5}$, J. Anibal Boscoboinik (10) ${ }^{2,4}$, D. Howard Fairbrother ${ }^{5}$ \& Michael Tsapatsis (1) 1,6凶

Patterning metal-organic frameworks (MOFs) at submicrometer scale is a crucial yet challenging task for their integration in miniaturized devices. Here we report an electron beam (ebeam) assisted, bottom-up approach for patterning of two MOFs, zeolitic imidazolate frameworks (ZIF), ZIF-8 and ZIF-67. A mild pretreatment of metal oxide precursors with linker vapor leads to the sensitization of the oxide surface to e-beam irradiation, effectively inhibiting subsequent conversion of the oxide to ZIFs in irradiated areas, while ZIF growth in nonirradiated areas is not affected. Well-resolved patterns with features down to the scale of $100 \mathrm{~nm}$ can be achieved. This developer-free, all-vapor phase technique will facilitate the incorporation of MOFs in micro- and nanofabrication processes.

\footnotetext{
${ }^{1}$ Department of Chemical and Biomolecular Engineering \& Institute for NanoBioTechnology, Johns Hopkins University, Baltimore, MD, USA. ${ }^{2}$ Center for Functional Nanomaterials, Brookhaven National Laboratory, Upton, NY, USA. ${ }^{3}$ Catalysis Center for Energy Innovation, University of Delaware, Newark, DE, USA. ${ }^{4}$ Department of Materials Science and Chemical Engineering, Stony Brook University, Stony Brook, NY, USA. ${ }^{5}$ Department of Chemistry, Johns Hopkins University, Baltimore, MD, USA. ${ }^{6}$ Applied Physics Laboratory, Johns Hopkins University, Laurel, MD, USA. ${ }^{7}$ These authors contributed equally:

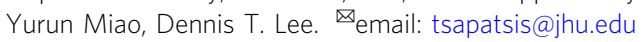


$\mathrm{M}$ OFs are isoreticular coordination networks assembled from metal ions and organic linkers ${ }^{1-3}$. They hold promise in applications including gas storage and separation $^{4-9}$, catalysis $^{10}$, drug delivery ${ }^{11}$, and energy conversion $^{12}$, due to their modular nature allowing for excellent tunability in the structural and chemical properties ${ }^{13}$. Hence, significant work has been dedicated to controlling the composition, dimensions, and positioning of MOF crystals and films by manipulating various synthetic parameters as well as introducing innovative approaches ${ }^{14,15}$. There is a long-standing interest in the development of patterning process for porous materials ${ }^{16-20}$, and in particular, MOF patterns with sub-micrometer scale precision offer unique advantages in their potential use in electronicand optical devices ${ }^{21-24}$. Recently, it has been demonstrated that amorphization of ZIFs, under X-ray ${ }^{25}$ and e-beam ${ }^{25-28}$ irradiations enables a selective removal of the irradiated or nonirradiated regions of the ZIFs in a liquid phase developing step. Deep X-ray lithography was also utilized to pattern ZIF films by selectively crosslinking a sol-gel bottom layer ${ }^{29}$. Despite these promising developments in top-down MOF patterning, there is no demonstration of bottom-up approaches using X-ray or ebeam, which have the potential to reach higher resolution than light-based systems with UV irradiation ${ }^{30}$ or with infrared laser writing ${ }^{31}$. Moreover, top-down patterning methods ${ }^{25-27,29}$ rely on irradiation-induced solubility change and subsequent removal of materials by dissolution. Yet, solvent-free approaches for patterning are currently at the forefront of technological needs due to their great potential in improving wafer processing efficiency and patterning quality at reduced material and energy $\cos ^{32}$. Although solvent-free MOF deposition steps have been incorporated in lift-off patterning 33,34 , fully solvent-free bottom-up patterning of MOFs will further facilitate their application in microfabrication processes.

Here, we report a developer-free, all-vapor, e-beam-induced area-selective bottom-up approach for the patterning of ZIFs. It achieves high precision (down to ca. $200 \mathrm{~nm}$ ZIF-8 line width and $100 \mathrm{~nm}$ gap in between) in ZIF position and size, outperforming other MOF bottom-up patterning approaches ${ }^{35-40}$ and broadening the applicability of e-beam MOF patterning.

\section{Results}

The processing technique employs the vapor-phase conversion of oxide films $\left(\mathrm{ZnO}\right.$ and $\mathrm{CoO}_{\mathrm{x}}$ ) to crystalline $\mathrm{ZIFs}$ using sublimated vapors of 2 -methylimidazole $(2 \mathrm{mIm})^{21,33}$. The key element introduced here is the pretreatment of the oxide layer with $2 \mathrm{mIm}$ at a relatively low temperature $\left(\mathrm{ca} .50^{\circ} \mathrm{C}\right.$ ) compared to the temperature used for ZIF crystallization (ca. $100^{\circ} \mathrm{C}$ ). This mild pretreatment aims to form an adsorbed $2 \mathrm{mIm}$ layer that sensitizes the oxide surface to e-beam treatment while avoiding ZIF crystallization. We hypothesize that the $2 \mathrm{mIm}$-sensitized oxide film can be altered by e-beam treatment to render it less reactive towards ZIF crystallization, allowing ZIF formation preferentially in the non-irradiated areas.

For the demonstration of the patterning process, we focus on ZIF-8, a prototypical ZIF (Fig. 1a). The area-selective patterning starts from a precursor layer of 15 -nm-thick zinc oxide deposited on a silicon substrate via atomic layer deposition (ALD) and consists of three consecutive steps: (i) the $\mathrm{ZnO}$ layer is sensitized by exposure to $2 \mathrm{mIm}$ vapor at relatively low temperature, $50{ }^{\circ} \mathrm{C}$ for $1 \mathrm{~h}$; (ii) the regions on the sensitized $\mathrm{ZnO}$ surface are irradiated using a direct-write focused e-beam $\left(2 \mathrm{keV}, 20 \mathrm{mC} \mathrm{cm}^{-2}\right)$; (iii) the sensitized and e-beam-patterned $\mathrm{ZnO}$ film is treated with $2 \mathrm{mIm}$ vapor at $100-120^{\circ} \mathrm{C}$ for $15-120 \mathrm{~min}$ to complete the patterning process by converting $\mathrm{ZnO}$ to $\mathrm{ZIF}-8$ in the non-irradiated area, while ZIF-8 growth in the e-beam irradiated area is inhibited.
As illustrated in Fig. 1b-d, well-defined ZIF-8 patterns with a variety of dimensions and shapes can be obtained. The patterns on silicon wafer substrates were characterized by atomic force microscopy (AFM) and scanning electron microscopy (SEM). AFM images show straight line patterns of polycrystalline ZIF-8 "ridges" in the non-irradiated areas and smooth, ZIF-8-free "trenches" coinciding with the e-beam irradiated area (Fig. 1b). The gap between ZIF-8 lines is as low as ca. $100 \mathrm{~nm}$ and the center-to-center spacing down to $300 \mathrm{~nm}$ (200 nm of ZIF-8 line and $100 \mathrm{~nm}$ of gap) were achieved. The thinnest lines obtained are about $200 \mathrm{~nm}$ in width and consist of small intergrown crystals.

Applying "hole" (disc and square) patterns in the e-beam writing process leads to the crystallization of ZIF- 8 in isolated regions, where poly- or single-crystalline ZIF-8 particles are arranged in a hexagonal or square lattice (Fig. 1c, d). The grain structure appears to be dependent on the size of non-irradiated "holes". ZIF-8 particles grown from a region smaller than $150 \mathrm{~nm}$ in size are mostly single crystalline (Fig. 1d), possibly due to a lower probability of multiple nucleation events in a single domain. Since the patterned deposit in this bottom-up approach is the outcome of crystal growth, the edge roughness of the deposit, the fidelity by which it fills the desired (non-irradiated areas), and the degree of spilling over to the irradiated areas, depend on the ability to control nucleation and growth in the non-irradiated areas. To improve ZIF pattern fidelity to the pattern created by e-beam irradiation, potential approaches include controlling the preferential orientation and the polycrystallinity (grain size) of the deposit. For example, we anticipate that if the grain size of the ZIF deposit can be reduced to a few unit cells (ca. $3 \mathrm{~nm}$ ), resolution in the $10 \mathrm{~nm}$ range can be achieved.

To allow for crystallographic studies, ZIF patterning on $50 \mathrm{~nm}$ thick silicon nitride windows was attempted (Fig. 2a). The obtained patterns were characterized by transmission electron microscopy (TEM) (Fig. 2b and Supplementary Fig. 1) and AFM (Fig. 2d), clearly displaying well-resolved polycrystalline structures. The slightly bright lining at the edge of the polycrystalline region shown in the TEM images is ascribed to the depletion of local $\mathrm{ZnO}$ precursor contributing to ZIF formation. In contrast, in the surrounding dark area, dense $\mathrm{ZnO}$ is well preserved. The crystallinity of the ZIF-8 deposit is confirmed by the ring patterns obtained with selected area electron diffraction (SAED) (Fig. 2c). $\mathrm{ZnO}$ remains smooth in an e-beam exposed area, and no diffraction is observed, indicating that the reactivity of $\mathrm{ZnO}$ to $2 \mathrm{mIm}$ can be suppressed entirely by the sequential combination of sensitization and e-beam irradiation.

A series of e-beam irradiations and $2 \mathrm{mIm}$ vapor treatments were investigated to assess the range for $\mathrm{ZIF}-8$ patterning. $\mathrm{A} \mathrm{ZnO}$ film sensitized with $2 \mathrm{mIm}$ was irradiated using an array of four squares $(2 \mu \mathrm{m} \times 2 \mu \mathrm{m})$ with different electron doses $(1,5,10$, and $20 \mathrm{mC} \mathrm{cm}^{-2}$, respectively) and subsequently exposed to $2 \mathrm{mIm}$ vapor at 100 and $130{ }^{\circ} \mathrm{C}$ for $15 \mathrm{~min}$ (Fig. 3a, b). At each temperature, the crystallization behavior was progressively altered by increased e-beam irradiation. The squares exposed to $1 \mathrm{mC} \mathrm{cm}^{-2}$ doses show slightly larger grains than those in the non-irradiated region. Increased irradiation leads to fewer and smaller crystals in each square. Upon reaching a threshold dose $\left(10 \mathrm{mC} \mathrm{cm}^{-2}\right.$ for $100^{\circ} \mathrm{C} 2 \mathrm{mIm}$ vapor treatment and $20 \mathrm{mC} \mathrm{cm}^{-2}$ for $130^{\circ} \mathrm{C} 2 \mathrm{mIm}$ vapor treatment), ZIF-8 formation is inhibited, and the surface within the irradiated squares is smooth and free of ZIF-8 crystals.

A cross-section of a region encompassing both ZIF-8 and ZIF8 -free adjacent areas (Fig. 3c) was prepared by focused ion beam (FIB) and examined by TEM (Fig. 3d, e) to elucidate the structure after the $2 \mathrm{mIm}$ vapor treatment. In the square irradiated with 20 $\mathrm{mC} \mathrm{cm}{ }^{-2}$, the $\mathrm{ZnO}$ film remains intact, confirming that its conversion to ZIF-8 is entirely suppressed by the e-beam 
a

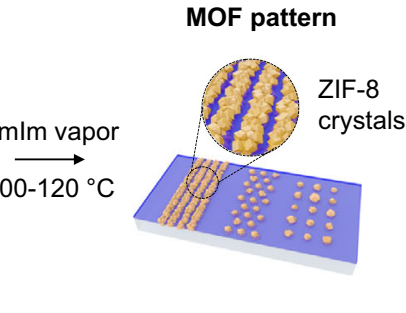

b

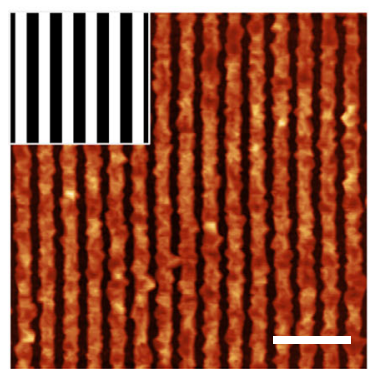

C

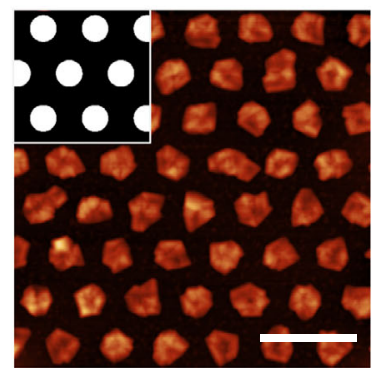

d

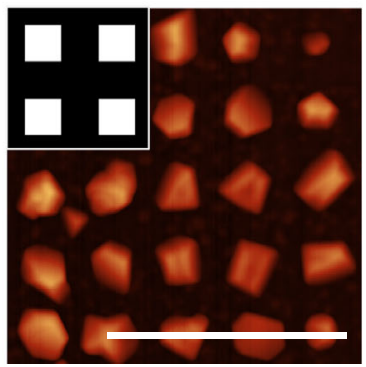

$80 \mathrm{~nm}$

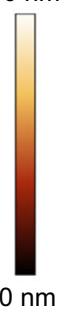

Fig. 1 ZIF-8 patterns prepared by area-selective deposition on silicon wafer substrates. a schematic illustration of the e-beam assisted area-selective deposition of ZIF-8, showing patterns with different designs. b AFM image of a line pattern with $150 \mathrm{~nm}$ width and $150 \mathrm{~nm}$ gap. c, d AFM images of ZIF-8 prepared by e-beam irradiation using a pattern of $\mathbf{c} 280 \mathrm{~nm}$ discs (corresponding to non-irradiated areas) in a hexagonal lattice and $\mathbf{d} 150-\mathrm{nm}$ squares (non-irradiated areas) arranged in a square lattice, respectively. Center-to-center distances between neighboring discs and squares are 560 and $300 \mathrm{~nm}$, respectively. Irradiated and non-irradiated areas are marked in black and white, respectively, in the top left inserts in $\mathbf{b}$, $\mathbf{c}$, and $\mathbf{d}$. All patterns in this figure were prepared by sensitizing $\mathrm{ZnO}$ with $2 \mathrm{mlm}$ at $50^{\circ} \mathrm{C}$ for $1 \mathrm{~h}$, followed by e-beam patterning $\left(2 \mathrm{keV}, 20 \mathrm{mC} \mathrm{cm}{ }^{-2}\right)$ and $2 \mathrm{mlm}$ vapor treatment at $100{ }^{\circ} \mathrm{C}$ for $15 \mathrm{~min}$. Scale bars are $1 \mu \mathrm{m}$.

irradiation. In contrast, the $\mathrm{ZnO}$ in the non-irradiated area is mostly consumed after the vapor treatment. In agreement with previous reports ${ }^{33,41}$, a thin unconverted layer of $\mathrm{ZnO}$ remains. It is located at the substrate- $\mathrm{ZnO}$ interface consistent with the proposed conversion of $\mathrm{ZnO}$ to ZIF-8 starting from the top of the film and propagating to the substrate- $\mathrm{ZnO}$ interface ${ }^{41}$. The presence of this thin unconverted layer could be beneficial for ensuring good adhesion of the ZIF-8 deposit to the substrate ${ }^{33}$. The ZIF-8 and ZIF-8-free areas are also clearly distinguished in SEM-EDS (Supplementary Fig. 2), corresponding to the $\mathrm{C} / \mathrm{N}$-rich and $\mathrm{C} / \mathrm{N}$-deficient areas respectively.

The duration of the ligand vapor treatment for ZIF-8 growth was extended beyond $15 \mathrm{~min}$ to investigate how the deposits evolve with time (Supplementary Figure 3). After $1 \mathrm{~h}$ at $100^{\circ} \mathrm{C}$, while the thickness of ZIF-8 in the non-irradiated area increases from 50 to $200 \mathrm{~nm}$ due to continued growth, the squares irradiated with 10 and $20 \mathrm{mC} \mathrm{cm}^{-2}$ are still smooth without significant nucleation. However, after $2 \mathrm{~h}$ at $120^{\circ} \mathrm{C}, \mathrm{ZIF}-8$ is present in all the irradiated squares, and the pattern cannot be distinguished from the background.

The adsorption of imidazole or its derivatives to carbon steel and copper has been studied in the context of enhancing anticorrosion efficiency ${ }^{42,43}$. For $\mathrm{ZnO}$, it was reported that a slight increase in film thickness (ca. $3 \mathrm{~nm}$ ) was observed by in-situ ellipsometry at the initial stage (ca. $10 \mathrm{~min}$ ) of the $2 \mathrm{mIm}$ vapor treatment of a $\mathrm{ZnO}$ thin film. This thickness increase was attributed to the sorption of $2 \mathrm{mIm}^{41}$. We systematically characterized samples obtained at various processing steps along the route to the selective ZIF growth to identify the species present on the $\mathrm{ZnO}$ film surface after the sensitization step and determine any changes in their chemical, morphological, and crystalline properties. In these experiments, the entire area of a sensitized $\mathrm{ZnO}$ film was exposed to the output of an electron gun operating at $2 \mathrm{kV}$ and characterized by AFM and grazing incidence X-ray diffraction (GIXD) (Fig. 4a, b). GIXD shows no evidence for crystallization throughout the sensitization and e-beam treatment process (Fig. 4a, traces for $\mathrm{ALD} \mathrm{ZnO}, \mathrm{ZnO}+\mathrm{s}, \mathrm{ZnO}+\mathrm{s}+\mathrm{e}$ ), while no change in roughness is found from AFM images both after sensitization $(\mathrm{ZnO}+\mathrm{s})$ and after e-beam irradiation $(\mathrm{ZnO}+\mathrm{s}+\mathrm{e})$ (Fig. 4b), confirming the absence of ZIF-8. The irradiated sample was further treated with $2 \mathrm{mIm}$ vapor at $120^{\circ} \mathrm{C}$ for $1 \mathrm{~h}(\mathrm{ZnO}+\mathrm{s}$ $+\mathrm{e}+2 \mathrm{mIm})$. After the $2 \mathrm{mIm}$ vapor treatment, the surface remains flat with only a few scattered small dots $(<10 \mathrm{~nm}$ in height). On the other hand, non-sensitized but e-beam irradiated $\mathrm{ZnO}(\mathrm{ZnO}+\mathrm{e}+2 \mathrm{mIm})$ shows uniform coverage of $\mathrm{ZIF}-8$ growth on the substrate after $2 \mathrm{mIm}$ vapor treatment, and so does $\mathrm{ZnO}$ with sensitization but without e-beam irradiation ( $\mathrm{ZnO}$ $+\mathrm{s}+2 \mathrm{mIm}$ ), clearly substantiating the necessity of both sensitization and e-beam treatment to selectively inhibit the $\mathrm{ZnO}$ conversion to ZIF-8. Infrared reflection absorption spectroscopy (IRRAS) results for the samples (Supplementary Fig. 4) also show a good agreement with the conclusions drawn from GIXD and AFM, especially in that the characteristic vibrational modes (1500-1200 $\mathrm{cm}^{-1}$ wavenumber) of the $2 \mathrm{mIm}$ in ZIF- 8 are mostly absent in the " $\mathrm{ZnO}+\mathrm{s}+\mathrm{e}+2 \mathrm{mIm}$ " sample, while they are present in " $\mathrm{ZnO}+\mathrm{e}+2 \mathrm{mIm}$ " and " $\mathrm{ZnO}+\mathrm{s}+2 \mathrm{mIm}$ " samples.

$\mathrm{X}$-ray photoelectron spectroscopy (XPS) was also performed to assess chemical changes on the surface of the samples (Fig. $4 \mathrm{c}$ and Supplementary Figs. 5-7). After the sensitization at $50^{\circ} \mathrm{C}$ for $1 \mathrm{~h}$ $(\mathrm{ZnO}+\mathrm{s})$, a peak appears at $398.8 \mathrm{eV}$ with a shoulder at $400.6 \mathrm{eV}$ in $\mathrm{N} 1 s$ XPS (Fig. 4c). The peak at $398.8 \mathrm{eV}$ corresponds to $\mathrm{N}$ in the unreacted imidazole molecule or $\mathrm{N}$ bound to $\mathrm{Zn}$, while the peak at $400.6 \mathrm{eV}$ is assigned to protonated $\mathrm{N}(\mathrm{N}-\mathrm{H})$. The different peak intensities could be a consequence of the adsorbate geometry with the bound $\mathrm{N}$ lying closest to the surface ${ }^{44}$. After e-beam irradiation $(\mathrm{ZnO}+\mathrm{s}+\mathrm{e})$, the overall intensity of the $\mathrm{N} 1 s$ region decreases, and the $\mathrm{N}-\mathrm{H}$ shoulder cannot be detected, possibly due to electron-induced deprotonation, desorption, and crosslinking of the adsorbed $2 \mathrm{mIm}^{45,46}$. The passivation is likely a result of the e-beam induced crosslinking that transforms the 
a
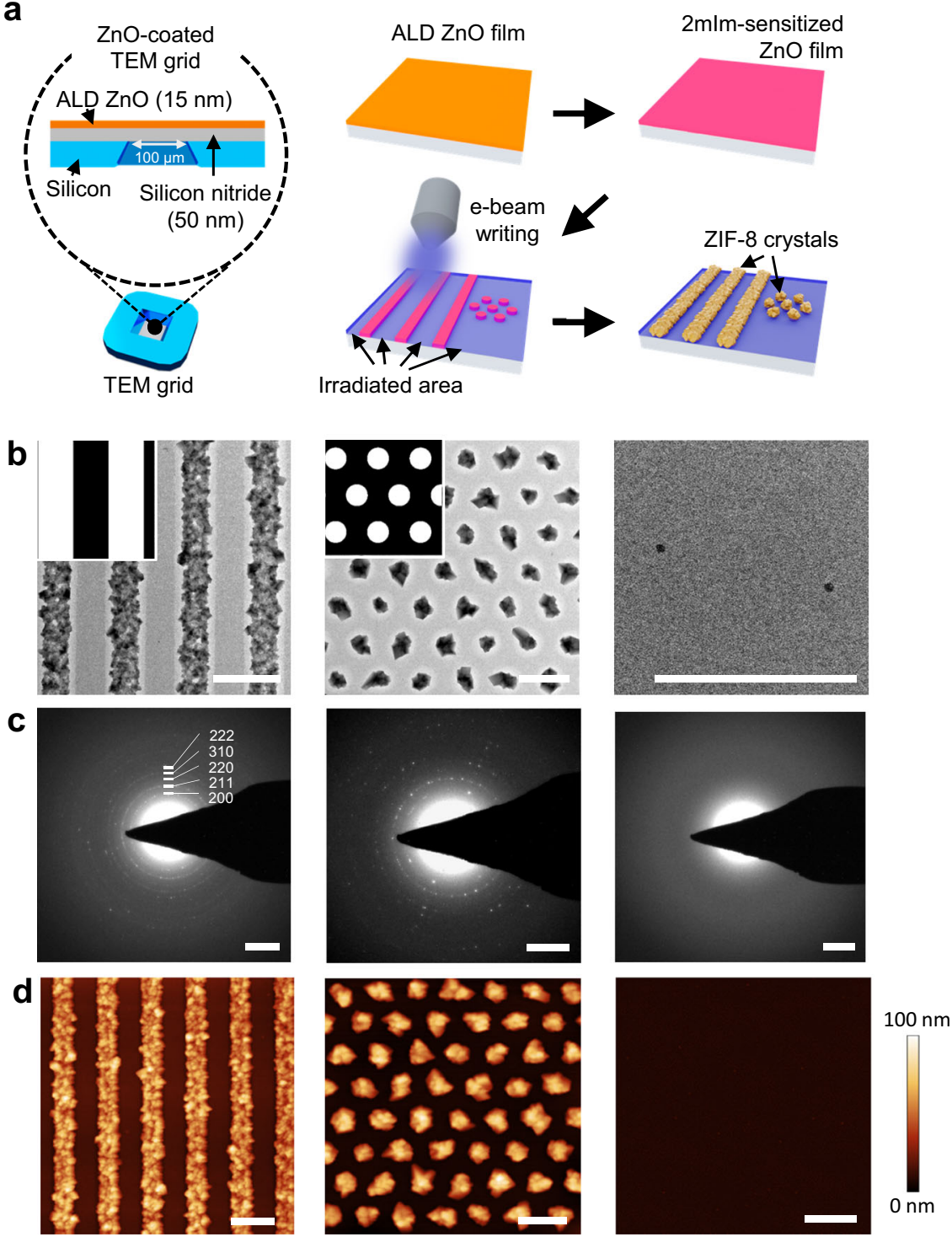

Fig. 2 ZIF-8 patterns on silicon nitride windows. a schematic illustration of the patterning process on silicon nitride substrate. $\mathbf{b}$ TEM images of line (500 nm width and $500 \mathrm{~nm}$ spacing) and dot (400 nm diameter and $400 \mathrm{~nm}$ spacing) patterns and a completely irradiated (non-growth) area, respectively. Irradiated and non-irradiated areas are marked in black and white, respectively, in the top left insets of line and dot patterns in $\mathbf{b}$. c SAED patterns of the imaged areas in $\mathbf{b}$; diffraction rings corresponding to ZIF-8 are indexed for the line pattern. $\mathbf{d}$ AFM height images of different areas on the silicon nitride window corresponding to the TEM images in $\mathbf{b}$. Scale bars are $1 \mu \mathrm{m}$ in $\mathbf{b}$ and $\mathbf{d}$, and $1 \mathrm{~nm}^{-1}$ in $\mathbf{c}$.

adsorbed $2 \mathrm{mIm}$ molecules into an oligomerized or polymeric coating, which inhibits the conversion of $\mathrm{ZnO}$ to $\mathrm{ZIF}-8$ in the irradiated area, while the non-irradiated $\mathrm{ZnO}$ surface remains reactive during the $2 \mathrm{mIm}$ vapor treatment. This crosslinking and partial desorption hypothesis is consistent with XPS data, which shows the disappearance of the $\mathrm{N}-\mathrm{H}$ component of the $\mathrm{N} 1 s$ region after e-beam exposure of the sensitized sample and a decrease in overall $\mathrm{N} 1 s$ intensity. The areal dose used in this study $\left(20 \mathrm{mC} \mathrm{cm}^{-2}\right.$ at $\left.2 \mathrm{kV}\right)$ is relatively high compared to typical resists used in e-beam lithography $\left(<1 \mathrm{mC} \mathrm{cm}^{-2}\right)^{47}$. Future research may focus on exploring similar adsorptive species with higher e-beam sensitivity to reduce the write time and improve the processing efficiency of this approach. The peak at $400.6 \mathrm{eV}$ reemerges after the vapor treatment $(\mathrm{ZnO}+\mathrm{s}+\mathrm{e}+2 \mathrm{mIm})$, probably because of $2 \mathrm{mIm}$ molecules adsorbed during the vapor treatment. In contrast, only the major peak at $398.7 \mathrm{eV}$, which is characteristic for ZIF- $8^{48}$, is observed in the samples lacking sensitization $(\mathrm{ZnO}+\mathrm{e}+2 \mathrm{mIm})$ or e-beam irradiation ( $\mathrm{ZnO}$ $+\mathrm{s}+2 \mathrm{mIm})$. This agrees well with the assignment of the low BE peak to $\mathrm{N}$ atoms forming part of the framework (bound to $\mathrm{Zn}$ ). Further analysis of C 1 s spectra (Supplementary Fig. 5) supports the hypothesis of crosslinking. $(\mathrm{ZnO}+\mathrm{s})$ shows three components at $284.8,285.5$, and $287.2 \mathrm{eV}$ assigned to $\mathrm{C}-\mathrm{C} / \mathrm{C}-\mathrm{H}, \mathrm{C}-\mathrm{N}$, and $\mathrm{C}-\mathrm{O}$ bonds, respectively. The latter indicates some $\mathrm{C}-\mathrm{O}-\mathrm{Zn}$ linkages upon sensitization with $2 \mathrm{mIm}$. Exposure to the e-beam $(\mathrm{ZnO}+\mathrm{s}+\mathrm{e})$ leads to a broadening of the component at $285.5 \mathrm{eV}$ assigned to $\mathrm{C}-\mathrm{N}$ bonds, which suggests the formation of species of different chemical environments ${ }^{49}$.

In the current approach, the passivated $\mathrm{ZnO}$ remains in the areas that do not convert to ZIF. For certain applications, the presence of $\mathrm{ZnO}$ may not be undesirable. For instance, when patterned MOFs are used as diffraction grating sensors, the diffraction intensity depends on the refractive index difference in different regions of the pattern ${ }^{25,50,51}$. The non-MOF part of the pattern can be either empty or filled with metal oxide $\mathrm{e}^{50}$ as long as there is a spatial contrast in the refractive index. 
a

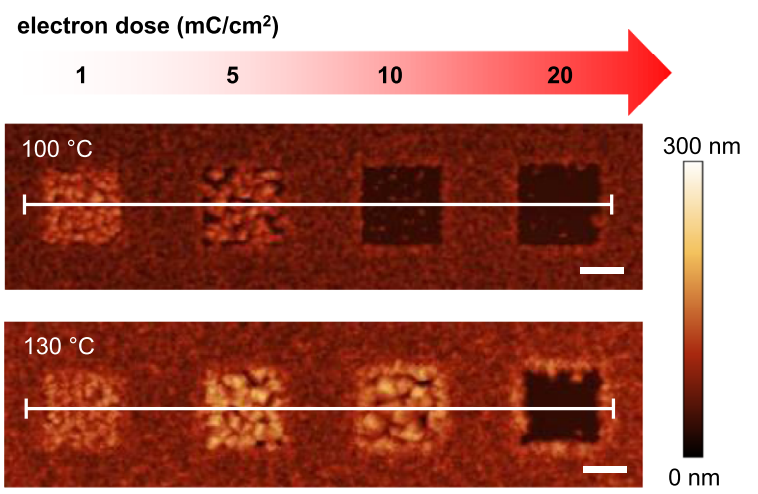

C

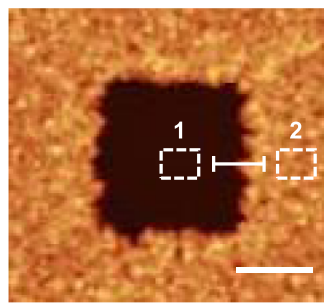

$300 \mathrm{~nm}$

d b

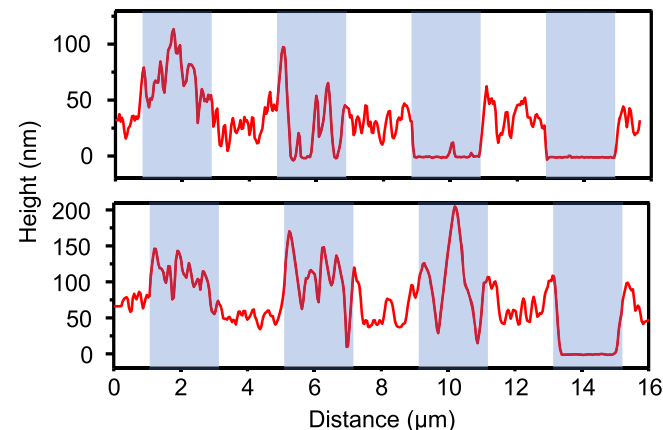

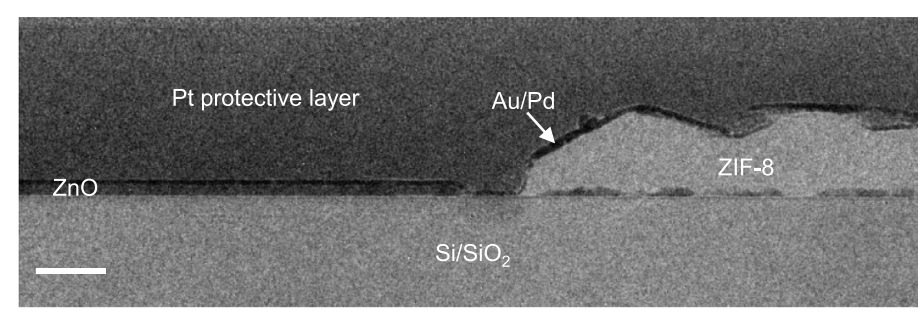

e
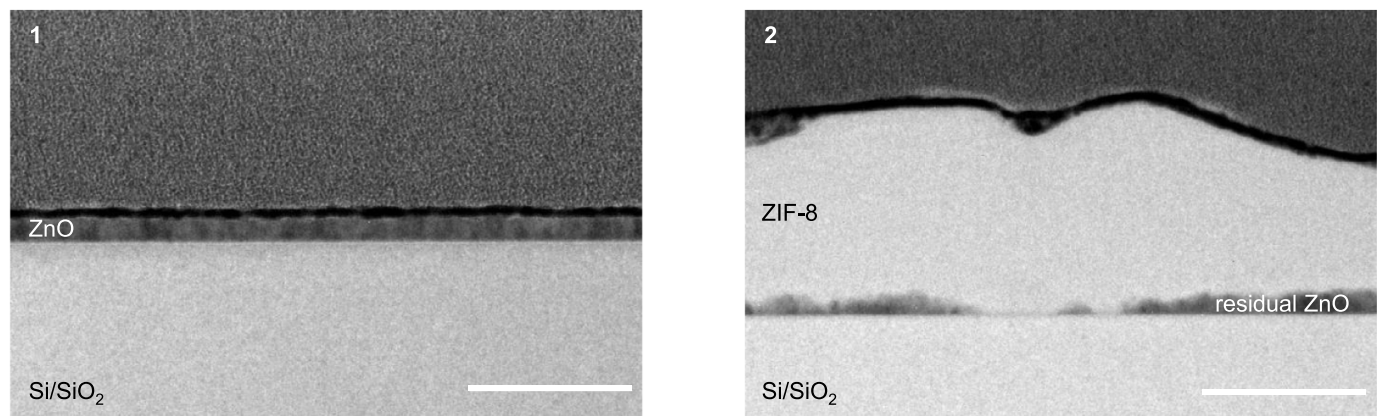

Fig. 3 ZIF-8 growth under various reaction conditions. a AFM height mapping of samples after vapor treatment at different temperatures. ZnO wafers are sensitized by $2 \mathrm{mlm}$ at $50{ }^{\circ} \mathrm{C}$ for $1 \mathrm{~h}$, and each of the four squares is irradiated with an electron dose of $1,5,10$ and $20 \mathrm{mC} \mathrm{cm}-2$ at $2 \mathrm{kV}$, respectively, before the vapor treatment with $2 \mathrm{mlm}$ at 100 or $130{ }^{\circ} \mathrm{C}$ for $15 \mathrm{~min}$. $\mathbf{b}$ line-scan profile across the marked trace for each sample in $\mathbf{a}$. Shaded regions correspond to areas irradiated by e-beam. c AFM image of a ZIF-8-free square in a ZIF-8 film prepared by sensitizing a ZnO wafer with $2 \mathrm{mlm}$ at $50^{\circ} \mathrm{C}$ for $1 \mathrm{~h}$, followed by e-beam irradiation ( $2 \mathrm{kV}, 20 \mathrm{mC} \mathrm{cm}^{-2}$ ) of a $2 \mu \mathrm{m} \times 2 \mu \mathrm{m}$ square and vapor treatment with $2 \mathrm{mlm}$ at $120^{\circ} \mathrm{C}$ for 15 min. $\mathbf{d}$, e TEM images of the cross-section prepared by FIB corresponding to the white line (d) and marked areas 1 and 2 (e) in $\mathbf{c}$. Scale bars are $1 \mu \mathrm{m}$ in $\mathbf{a}$ and $\mathbf{c}$, and $100 \mathrm{~nm}$ in $\mathbf{d}$ and $\mathbf{e}$

A sensitization approach was introduced and demonstrated to enable e-beam-based bottom-up patterning of ZIF-8. It relies on finding a window of processing conditions that allow linker incorporation in the precursor oxide film without causing ZIF-8 nucleation. The subsequent writing with an e-beam passivates the exposed areas and determines where ZIF- 8 would nucleate and grow. This method should be in principle applicable to other ZIFs and MOFs. In preliminary experiments, we demonstrate feasibility for patterning of ZIF-67, a Co ZIF, by following similar treatment steps (but with adjustments in duration) as for ZIF-8 while using cobalt oxide $\left(\mathrm{CoO}_{x}\right)$ as the substrate. First, an ALD $\mathrm{CoO}_{x}$ film was sensitized with $2 \mathrm{mIm}$ at $50^{\circ} \mathrm{C}$ for $2 \mathrm{~h}$. AFM images show that the surface roughness of $\mathrm{CoO}_{x}$ remains essentially unchanged after sensitization (Fig. 5a). After e-beam irradiation $\left(2 \mathrm{kV}, 20 \mathrm{mC} \mathrm{cm}^{-2}\right)$ and subsequent vapor treatment with $2 \mathrm{mIm}$ at $120^{\circ} \mathrm{C}$ for $2 \mathrm{~h}$ (Fig. 5b), the irradiated area remains smooth as opposed to the significantly roughened nonirradiated area due to the growth of ZIF-67. Consistently, SEMEDS shows a relatively lower content of $\mathrm{C}$ and $\mathrm{N}$ in the irradiated area due to the lack of $\mathrm{CoO}_{x}$ conversion to ZIF-67 (Supplementary Fig. 8).

\section{Methods}

Materials. 2-methylimidazole (2mIm, 99\%) was purchased from Sigma Aldrich. Diethylzinc (DEZ, 95\% purity), tetrakis(dimethylamino)zirconium(IV) (TDMAZ, $99 \%$ purity), and bis( $N$ - $t$-butyl- $N^{\prime}$-ethylpropanimidamidato)cobalt(II) (Co(AMD) ${ }_{2}$, min. 98\%) were purchased from STREM chemicals Inc. Homemade Milli-Q DIwater $\left(\mathrm{H}_{2} \mathrm{O}\right)$ was used. Silicon wafers were purchased from UniversityWafer Inc. and silicon nitride supports $(50 \mathrm{~nm}$ silicon nitride film on a $200 \mu \mathrm{m}$ silicon frame with nine viewing windows, each $0.1 \times 0.1 \mathrm{~mm}$ ) for transmission electron microscopy (TEM) were purchased from Ted Pella.

Atomic layer deposition (ALD) on planar substrates. Several pieces of $\mathrm{Si}$ wafer $(1 \mathrm{~cm} \times 1 \mathrm{~cm}$ size $)$ with thin native oxide $(\sim 2 \mathrm{~nm})\left(\mathrm{Si}_{/} \mathrm{SiO}_{2}\right)$ and silicon nitride supports were loaded into the ALD reactor (Savannah S200, Veeco Instruments Inc.). Prior to the ALD processes, the silicon nitride supports were treated with oxygen plasma ( $29.6 \mathrm{~W}, 400 \mathrm{mTorr})$ for $10 \mathrm{~min}$ to improve the surface reactivity with ALD precursors using a plasma cleaner (Harrick Plasma).

The inorganic $\mathrm{ZnO}$ thin film was deposited with $\mathrm{H}_{2} \mathrm{O} / \mathrm{DEZ}$ precursor pulses separated by Ar purge in between. The sequence time (in second) of " $\mathrm{H}_{2} \mathrm{O}$ pulse/ $\mathrm{Ar}$ purge/DEZ pulse/Ar purge" was "0.015/5/0.015/5" for $\mathrm{ZnO}$ deposition. The $\mathrm{ZnO}$ coated $\mathrm{Si}$ wafers were prepared with 100 cycles of ALD $\mathrm{ZnO}$ to the $\mathrm{Si} / \mathrm{SiO}_{2}$ at $125^{\circ} \mathrm{C}$ under $\sim 0.270$ Torr. Around $15 \mathrm{~nm}$ of $\mathrm{ZnO}$ film on the $\mathrm{Si} / \mathrm{SiO}_{2}$ was confirmed from an FS-1 Multi-Wavelength Ellipsometer System.

In addition, $\mathrm{CoO}_{x}$ film deposition was performed separately. To provide enough vapor pressure of $\operatorname{Co}(\mathrm{AMD})_{2}$ during the film deposition, a stainless-steel cylinder container with the metal precursor was heated to $100^{\circ} \mathrm{C}$, and the vapor was doubly 
a

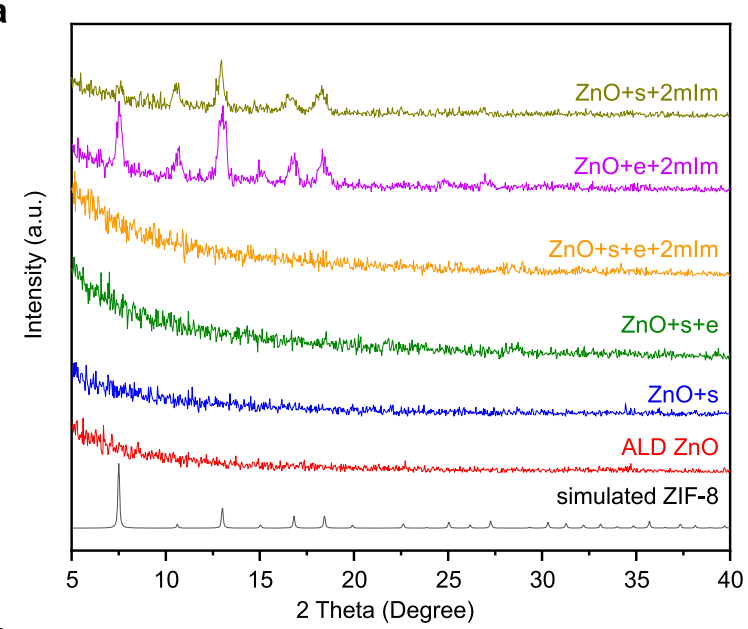

b

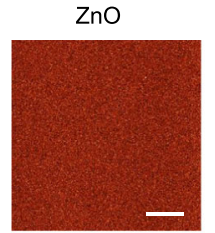

$\mathrm{ZnO}+\mathrm{s}+\mathrm{e}+2 \mathrm{mlm}$

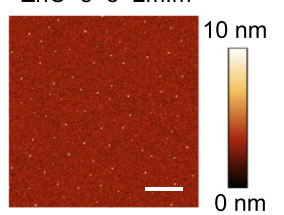

$\mathrm{ZnO}+\mathrm{s}$

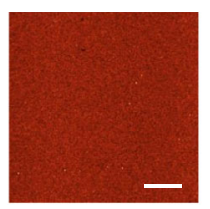

$\mathrm{ZnO}+\mathrm{e}+2 \mathrm{mlm}$

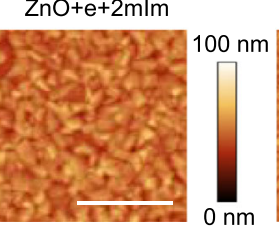

$\mathrm{ZnO}+\mathrm{s}+\mathrm{e}$

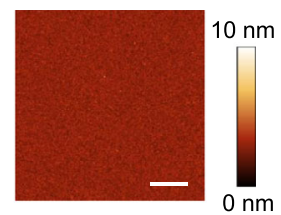

$\mathrm{ZnO}+\mathrm{s}+2 \mathrm{mlm}$

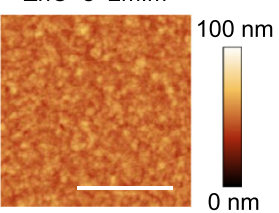

C
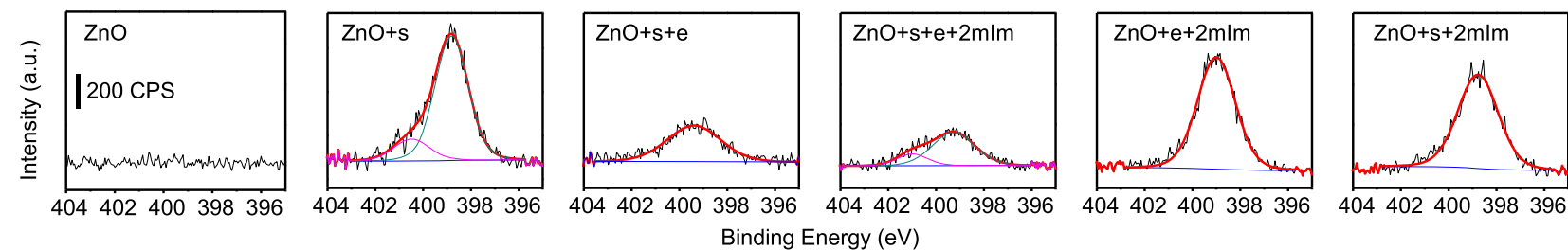

Fig. 4 Characterization of sensitized and e-beam irradiated ZnO samples. $\mathbf{a}$, b GIXD and AFM of a ZnO wafer before and after consecutive treatment of sensitization, e-beam irradiation, and $2 \mathrm{mlm}$ treatment. Samples are denoted to indicate the processing steps used, s: sensitization with $2 \mathrm{mlm}$ at $50{ }^{\circ} \mathrm{C}$ for $1 \mathrm{~h}$; e: e-beam irradiation at $2 \mathrm{kV}, 20 \mathrm{mC} \mathrm{cm}-2 ; 2 \mathrm{mlm}$ : vapor treatment with $2 \mathrm{mlm}$ at $120^{\circ} \mathrm{C}$ for $15 \mathrm{~min}$. GIXD patterns were collected at a $0.15^{\circ}$ incidence angle. c. $N$ 1s XPS of samples corresponding to a. Scale bars are $1 \mu \mathrm{m}$.

a

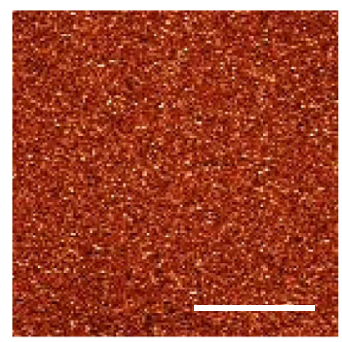

after sensitization

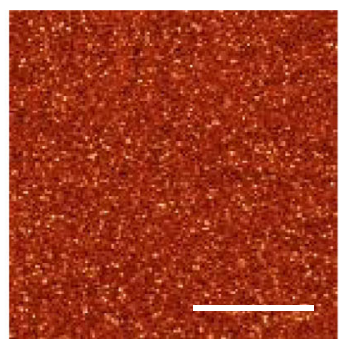

b

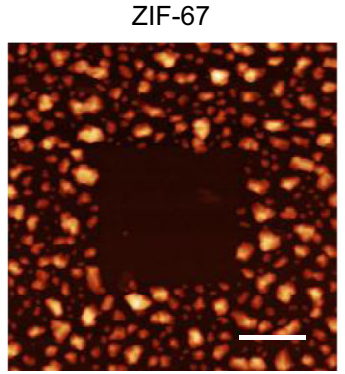

$150 \mathrm{~nm}$

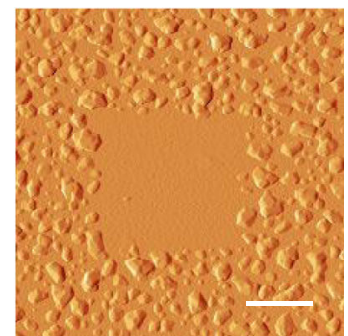

Fig. 5 Selective deposition of ZIF-67 from $\mathbf{C o O}_{\mathbf{x}}$. a AFM images of an ALD $\mathrm{CoO}_{x}$ film before and after sensitization with $2 \mathrm{mlm}$ at $50{ }^{\circ} \mathrm{C}$ for $2 \mathrm{~h}$. $\mathbf{b}$ AFM height (left) and amplitude error (right) images of a ZIF-free area on a ZIF- 67 film, prepared by e-beam irradiation $\left(2 \mathrm{kV}, 20 \mathrm{mC} \mathrm{cm}^{-2}\right)$ of a sensitized $\mathrm{CoO}_{x}$ sample in a $2 \mu \mathrm{m} \times 2 \mu \mathrm{m}$ square, followed by vapor treatment with $2 \mathrm{mlm}$ at $120^{\circ} \mathrm{C}$ for $2 \mathrm{~h}$. Scale bars are $1 \mu \mathrm{m}$.

pulsed to the reactor. Around $20 \mathrm{~nm}$ of $\mathrm{ZrO}_{2}$ film as an adhesion layer was deposited to $\mathrm{Si} / \mathrm{SiO}_{2}$ substrates prior to the $\mathrm{CoO}_{x}$ ALD processes to enhance film uniformity. The $\mathrm{CoO}_{x}$-coated samples were prepared with 150 cycles of ALD $\mathrm{CoO}_{x}$ to the $\mathrm{ZrO}_{2} /\left(\mathrm{Si}_{\mathrm{SiO}}\right)$ at $150^{\circ} \mathrm{C}$ under $\sim 0.570$ Torr. The sequence time (in seconds) of " $\mathrm{H}_{2} \mathrm{O}$ pulse/Ar purge/(Co(AMD $)_{2}$ pulse/Ar purge $) \times 2$ " was " $0.015 / 5 /(0.5 / 20) \times 2$ " for $\mathrm{CoO}_{x}$ deposition. Around $9 \mathrm{~nm}$ of $\mathrm{CoO}_{x}$ film on the $\mathrm{ZrO}_{2} /\left(\mathrm{Si}_{/} / \mathrm{SiO}_{2}\right)$ was confirmed from an FS-1 Multi-Wavelength Ellipsometer System.

Sensitization of metal oxide thin film. The prepared metal oxide-coated samples were placed on a stainless-steel mesh holder and transferred to a cylindrical quartz reactor system. First, $0.2 \mathrm{~g}$ of $2 \mathrm{mIm}$ solid was loaded at the bottom of the reactor. The reactor was then connected to a vacuum pump via a manual valve, and the whole set-up was placed in the oven. The system was flushed with an Ar gas $(100 \mathrm{sccm})$ at room temperature under a dynamic vacuum $(\sim 50 \mathrm{mbar})$ for $15 \mathrm{~min}$. After that, the Ar flushing was stopped, and the reactor was evacuated for $5 \mathrm{~min}$ until the system pressure stabilizes at the base pressure ( 10 mbar). Then, the valve to the vacuum pump was closed, followed by flowing the Ar to the system until the system pressure reaches around $1 \mathrm{bar}$. The reactor was heated at $50^{\circ} \mathrm{C}$ for $1 \mathrm{~h}$ and then cooled down to room temperature.

E-beam patterning. E-beam exposure experiments were performed on a ThermoFisher Helios G4 UC Focused Ion Dual Beam microscope. Patterning was performed on the sensitized samples at $2 \mathrm{kV}$ acceleration voltage with $100 \mathrm{pA}$ probe current. All patterns were exposed at $1 \mu$ s dwell time and $2.2 \mathrm{~nm}$ pitch size, while the pass (scan) number was varied in each exposure to obtain the desired electron dose.

ZIF film growth. The e-beam patterned samples were placed on a stainless-steel mesh holder and transferred to a quartz reactor system. The system was flushed with an $\mathrm{Ar}$ gas and evacuated under a vacuum in the same way as the metal oxide sensitization process. After that, the valve to the vacuum pump was closed, followed by heating the reactor at $120^{\circ} \mathrm{C}$ for $2 \mathrm{~h}$ under static vacuum. After the reaction is over, the reactor was cooled down to room temperature. The produced films were stored in a desiccator before being used for further characterizations.

E-beam irradiation. The entire surface of wafers was irradiated in a home-built UHV system equipped with an electron gun (ELG-2, Kimball Physics) mounted on a UHV chamber. Wafer samples were loaded into the UHV chamber and evacuated overnight before irradiation. Chamber pressure was kept below $1 \times 10^{-7}$ mTorr during irradiation. Beam parameters were controlled by a separate power supply unit (EGPS-1022, Kimball Physics). The emission current was set at $17.2 \mu \mathrm{A}$, corresponding to an electron flux of $1.6 \mu \mathrm{A} \mathrm{cm}^{-2}$ at $30 \mathrm{~mm}$ spot size and $100 \mathrm{~mm}$ working distance. 
Characterization. Grazing Incidence X-ray Diffraction (GIXD) analysis of the thin film materials was performed using a Rigaku Smartlab (Instrument at BNL). Films were scanned at $40 \mathrm{kV}$ and $45 \mathrm{~mA}$ using $\mathrm{Cu} \mathrm{Ka}$ radiation $(\lambda=1.54 \AA)$ and a step size of $2 \theta=0.04^{\circ}\left(2^{\circ} \mathrm{min}^{-1}\right)$ over a $2 \theta$ range of $5-40^{\circ}$. Incidence angles varied from 0.1 to $0.20^{\circ}$. AFM images were collected on a Bruker Multimode 8 with a Si tip at a scan rate of $1 \mathrm{~Hz}$ and 256 lines/scan under tapping mode. Around $2.5 \mathrm{~nm} \mathrm{Au} / \mathrm{Pd}$ coating was deposited on all the Si wafer-based samples using a Leica EM ACE600 sputter for obtaining scanning electron microscopy (SEM) images. The SEM images and energy-dispersive X-ray spectroscopy (EDS) data were collected using a ThermoFisher Helios G4 UC Focused Ion Dual Beam microscope. TEM images and ED patterns were obtained on a ThermoFisher TF30 TEM operating at $300 \mathrm{kV}$. X-ray photoelectron spectroscopy (XPS) experiments were performed using a system equipped with a SPECS PHOIBOS NAP 150 hemispherical analyzer and a monochromatic $\mathrm{Al} \mathrm{Ka} \mathrm{X-ray} \mathrm{source.} \mathrm{The} \mathrm{spectra} \mathrm{were} \mathrm{acquired} \mathrm{under} \mathrm{UHV}$ conditions (base pressure of $2 \times 10^{-9} \mathrm{mbar}$ ) and $298 \mathrm{~K}$ on sample areas smaller than $300 \mu \mathrm{m} \times 300 \mu \mathrm{m}$. The spectra were calibrated using C $1 s$ main peak at $284.8 \mathrm{eV}$ as reference. Infrared reflection absorption spectroscopy (IRRAS) was performed in a Bruker Vertex $80 \mathrm{~V}$ spectrometer at grazing incidence $\left(8^{\circ}\right)$ under UHV (base pressure of $2 \times 10^{-9} \mathrm{mbar}$ ) and a mercury-cadmium-telluride (MCT) detector located in an external chamber. The spectra were collected for wavelengths in the range of $800-4000 \mathrm{~cm}^{-1}$ with 500 scans and a $4 \mathrm{~cm}^{-1}$ resolution. In this work, the $s$-polarized spectrum was collected as background and subtracted from the $p$-polarized spectrum for all experiments.

\section{Data availability}

The data that support the findings of this study are available in the article or its Supplementary File, or available from the corresponding author on request.

Received: 10 August 2021; Accepted: 21 December 2021;

Published online: 20 January 2022

\section{References}

1. Furukawa, H., Cordova, K. E., O'Keeffe, M. \& Yaghi, O. M. The chemistry and applications of metal-organic frameworks. Science 341, 1230444 (2013).

2. Kitagawa, S., Kitaura, R. \& Noro, S. Functional porous coordination polymers. Angew. Chem. Int. Ed. 43, 2334-2375 (2004).

3. Férey, G. Hybrid porous solids: past, present, future. Chem. Soc. Rev. 37, 191-214 (2008).

4. Ma, X. et al. Zeolitic imidazolate framework membranes made by ligandinduced permselectivation. Science 361, 1008-1011 (2018).

5. Kwon, H. T. \& Jeong, H. K. In situ synthesis of thin zeolitic-imidazolate framework ZIF-8 membranes exhibiting exceptionally high propylene/ propane separation. J. Am. Chem. Soc. 135, 10763-10768 (2013).

6. Brown, A. J. et al. Interfacial microfluidic processing of metal-organic framework hollow fiber membranes. Science 345, 72-75 (2014).

7. Knebel, A. et al. Defibrillation of soft porous metal-organic frameworks with electric fields. Science 358, 347-351 (2017).

8. He, G., Dakhchoune, M., Zhao, J., Huang, S. \& Agrawal, K. V. Electrophoretic nuclei assembly for crystallization of high-performance membranes on unmodified supports. Adv. Funct. Mater. 28, 1-8 (2018).

9. Wei, R. et al. Aqueously cathodic deposition of ZIF-8 membranes for superior propylene/propane separation. Adv. Funct. Mater. 30, 1-7 (2020).

10. Wei, Y. S., Zhang, M., Zou, R. \& Xu, Q. Metal-organic framework-based catalysts with single metal sites. Chem. Rev. 120, 12089-12174 (2020).

11. Wu, M. X. \& Yang, Y. W. Metal-organic framework (MOF)-based drug/cargo delivery and cancer therapy. Adv. Mater. 29, 1-20 (2017).

12. Lu, X. F., Fang, Y., Luan, D. \& Lou, X. W. D. Metal-organic frameworks derived functional materials for electrochemical energy storage and conversion: a mini review. Nano Lett. 21, 1555-1565 (2021).

13. Feng, L., Wang, K. Y., Powell, J. \& Zhou, H. C. Controllable synthesis of metal-organic frameworks and their hierarchical assemblies. Matter 1, 801-824 (2019).

14. Falcaro, P. et al. MOF positioning technology and device fabrication. Chem. Soc. Rev. 43, 5513-5560 (2014).

15. Furukawa, S., Reboul, J., Diring, S., Sumida, K. \& Kitagawa, S. Structuring of metal-organic frameworks at the mesoscopic/macroscopic scale. Chem. Soc. Rev. 43, 5700-5734 (2014)

16. Wang, H., Wang, Z., Huang, L., Mitra, A. \& Yan, Y. Surface patterned porous films by convection-assisted dynamic self-assembly of zeolite nanoparticles. Langmuir 17, 2572-2574 (2001).

17. Naydenova, I. et al. Hybrid sensors fabricated by inkjet printing and holographic patterning. Chem. Mater. 27, 6097-6101 (2015).

18. Hermes, S., Schröder, F., Chelmowski, R., Wöll, C. \& Fischer, R. A. Selective nucleation and growth of metal-organic open framework thin films on patterned $\mathrm{COOH} / \mathrm{CF} 3$-terminated self-assembled monolayers on $\mathrm{Au}(111) . \mathrm{J}$. Am. Chem. Soc. 127, 13744-13745 (2005).

19. Huang, L. et al. Fabrication of ordered porous structures by self-assembly of zeolite nanocrystals. J. Am. Chem. Soc. 122, 3530-3531 (2000).

20. Yoo, Y. \& Jeong, H.-K. Rapid fabrication of metal organic framework thin films using microwave-induced thermal deposition. Chem. Commun. 2441 https://doi.org/10.1039/b800061a (2008).

21. Krishtab, M. et al. Vapor-deposited zeolitic imidazolate frameworks as gapfilling ultra-low-k dielectrics. Nat. Commun. 10, 1-9 (2019).

22. Usman, M., Mendiratta, S. \& Lu, K. L. Semiconductor metal-organic frameworks: future low-bandgap materials. Adv. Mater. 29, 1-5 (2017).

23. Stassen, I. et al. An updated roadmap for the integration of metal-organic frameworks with electronic devices and chemical sensors. Chem. Soc. Rev. 46, 3185-3241 (2017).

24. Stavila, V., Talin, A. A. \& Allendorf, M. D. MOF-based electronic and optoelectronic devices. Chem. Soc. Rev. 43, 5994-6010 (2014).

25. Tu, M. et al. Direct X-ray and electron-beam lithography of halogenated zeolitic imidazolate frameworks. Nat. Mater. 20, 93-99 (2021).

26. Conrad, S. et al. Controlling dissolution and transformation of zeolitic imidazolate frameworks by using electron-beam-induced amorphization. Angew. Chem. Int. Ed. 57, 13592-13597 (2018).

27. Miao, Y. \& Tsapatsis, M. Electron beam patterning of metal-organic frameworks. Chem. Mater. 33, 754-760 (2021).

28. Ghosh, S. et al. Two distinct stages of structural modification of ZIF-L MOF under electron-beam irradiation. Chem. Mater. 33, 5681-5689 (2021).

29. Dimitrakakis, C. et al. Top-down patterning of zeolitic imidazolate framework composite thin films by deep X-ray lithography. Chem. Commun. 48, 7483-7485 (2012)

30. Keitz, B. K., Yu, C. J., Long, J. R. \& Ameloot, R. Lithographic deposition of patterned metal-organic framework coatings using a photobase generator. Angew. Chem. Int. Ed. 53, 5561-5565 (2014).

31. Hirai, K. \& Sada, K. Infrared laser writing of MOFs. Chem. Commun. 53, 5275-5278 (2017)

32. Wise, R. S. Breaking stochastic tradeoffs with a dry deposited and dry developed EUV photoresist system. In Advances in Patterning Materials and Processes XXXVIII (eds. Guerrero, D. \& Sanders, D. P.) Vol. 11612031 (SPIE, 2021).

33. Stassen, I. et al. Chemical vapour deposition of zeolitic imidazolate framework thin films. Nat. Mater. 15, 304-310 (2016).

34. Ruiz-Zambrana, C. L., Malankowska, M. \& Coronas, J. Metal organic framework top-down and bottom-up patterning techniques. Dalt. Trans. 49, 15139-15148 (2020).

35. Li, S. et al. Unconventional nucleation and oriented growth of ZIF-8 crystals on non-polar surface. Adv. Mater. 24, 5954-5958 (2012).

36. Zhuang, J., Friedel, J. \& Terfort, A. The oriented and patterned growth of fluorescent metal-organic frameworks onto functionalized surfaces. Beilstein $J$ Nanotechnol. 3, 570-578 (2012)

37. Ameloot, R. et al. Metal-organic framework single crystals as photoactive matrices for the generation of metallic microstructures. Adv. Mater. 23 , 1788-1791 (2011)

38. Armon, N. et al. Simultaneous laser-induced synthesis and micro-patterning of a metal organic framework. Chem. Commun. 55, 12773-12776 (2019).

39. Lu, G., Farha, O. K., Zhang, W., Huo, F. \& Hupp, J. T. Engineering ZIF-8 thin films for hybrid MOF-based devices. Adv. Mater. 24, 3970-3974 (2012).

40. Carbonell, C., Imaz, I. \& Maspoch, D. Single-crystal metal-organic framework arrays. J. Am. Chem. Soc. 133, 2144-2147 (2011).

41. Cruz, A. J. et al. Integrated cleanroom process for the vapor-phase deposition of large-area zeolitic imidazolate framework thin films. Chem. Mater. 31, 9462-9471 (2019)

42. Lee, W. J. Inhibiting effects of imidazole on copper corrosion in $1 \mathrm{M}$ HNO3 solution. Mater. Sci. Eng. A 348, 217-226 (2003).

43. Dutta, A., Saha, S. K., Adhikari, U., Banerjee, P. \& Sukul, D. Effect of substitution on corrosion inhibition properties of 2-(substituted phenyl) benzimidazole derivatives on mild steel in $1 \mathrm{M} \mathrm{HCl}$ solution: a combined experimental and theoretical approach. Corros. Sci. 123, 256-266 (2017).

44. Finšgar, M. 2-Mercaptobenzimidazole as a copper corrosion inhibitor: Part II Surface analysis using X-ray photoelectron spectroscopy. Corros. Sci. 72, 90-98 (2013).

45. Higuchi, T. et al. One-step nanopatterning of conjugated polymers by electron-beam-assisted electropolymerization. Microscopy 64, 205-212 (2015).

46. Wang, H. L., O'Malley, R. M. \& Fernandez, J. E. Electrochemical and chemical polymerization of imidazole and some of its derivatives. Macromolecules 27, 893-901 (1994).

47. Gangnaik, A. S., Georgiev, Y. M. \& Holmes, J. D. New generation electron beam resists: a review. Chem. Mater. 29, 1898-1917 (2017).

48. Liu, S., Xiang, Z., Hu, Z., Zheng, X. \& Cao, D. Zeolitic imidazolate framework8 as a luminescent material for the sensing of metal ions and small molecules. J. Mater. Chem. 21, 6649-6653 (2011). 
49. Kiciński, W. \& Dyjak, S. Nitrogen-doped carbons derived from imidazolebased cross-linked porous organic polymers. Molecules 26, 668 (2021).

50. Dalstein, O. et al. Nanoimprinted, submicrometric, MOF-based 2D photonic structures: toward easy selective vapors sensing by a smartphone camera. $A d v$. Funct. Mater. 26, 81-90 (2016).

51. Dalstein, O. et al. Evaporation-directed crack-patterning of metal-organic framework colloidal films and their application as photonic sensors. Angew. Chem. Int. Ed. 56, 14011-14015 (2017).

\section{Acknowledgements}

This material is based upon work supported by the U.S. Department of Energy, Office of Science, Office of Basic Energy Sciences, Division of Chemical Sciences, Geosciences and Biosciences under Award DE-SC0021212 and Award DE-SC0021304. XPS data collection and analysis was partially supported by the Catalysis Center for Energy Innovation, an Energy Frontier Research Center funded by the U.S. Department of Energy, Office of Science, Office of Basic Energy Sciences under Award No. DE-SC0001004. Surface characterization carried out in part at Center for Functional Nanomaterials at Brookhaven National Laboratory, supported by the U.S. Department of Energy, Office of Basic Energy Sciences, under Contract No. DE-SC0012704. M.T. and D.H.F. acknowledge partial support from a 2019 JHU Discovery Award (Design of Interfaces between Porous and Non-Porous Materials for Energy Applications).

\section{Author contributions}

M.T. conceived and directed the project. Patterning experiments were designed by M.T., Y.M., and D.T.L. Experiments and data analysis on MOF patterning was performed by Y.M. and D.T.L. GIXD and XPS experiments were performed by M.D.d.M. and M.A. and analyzed with input from J.A.B. and D.H.F. IRRAS experiments were directed by J.A.B. E-beam experiments on entire wafers were performed by M.K.A.-R, P.M.E., and Y.M. under D.H.F. direction. The manuscript was written mainly by Y.M. and D.T.L. with contributions by M.T. and input from all authors.

\section{Competing interests}

The authors declare no competing interests.

\section{Additional information}

Supplementary information The online version contains supplementary material available at https://doi.org/10.1038/s41467-022-28050-z.

Correspondence and requests for materials should be addressed to Michael Tsapatsis.

Peer review information Nature Communications thanks the anonymous reviewer(s) for their contribution to the peer review of this work. Peer reviewer reports are available.

Reprints and permission information is available at http://www.nature.com/reprints

Publisher's note Springer Nature remains neutral with regard to jurisdictional claims in published maps and institutional affiliations.

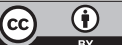

Open Access This article is licensed under a Creative Commons Attribution 4.0 International License, which permits use, sharing, adaptation, distribution and reproduction in any medium or format, as long as you give appropriate credit to the original author(s) and the source, provide a link to the Creative Commons license, and indicate if changes were made. The images or other third party material in this article are included in the article's Creative Commons license, unless indicated otherwise in a credit line to the material. If material is not included in the article's Creative Commons license and your intended use is not permitted by statutory regulation or exceeds the permitted use, you will need to obtain permission directly from the copyright holder. To view a copy of this license, visit http://creativecommons.org/ licenses/by/4.0/.

(C) The Author(s) 2022 